\title{
Percepção de professores das salas de recursos em uma rede de ensino municipal do Paraná
}

\author{
Adriana Zilly* \\ Leonardo Pereira Triaca** \\ Jossiana Wilke Faller*** \\ Reinaldo Antonio da Silva Sobrinho**** \\ Marieta Fernandes Santos***** \\ Maria de Lourdes de Almeida ${ }^{* * * * *}$
}

\section{Resumo}

Esta pesquisa analisou a percepção dos professores, que atuam nas salas de recursos (SR) das escolas municipais de Foz do Iguaçu/PR, sobre a inclusão escolar de crianças com Necessidades Educacionais Especiais (NEEs). Trata-se de uma pesquisa quantiqualitativa, com utilização da técnica do Discurso do Sujeito Coletivo (DSC). Os dados foram coletados no primeiro semestre de 2012, por meio de questionários aplicados aos professores da rede municipal. Para a análise descritiva das falas, os resultados foram organizados em planilhas. Identificaram-se serviços bem estruturados, demonstrando uma grande preocupação em nível de políticas públicas sobre a perspectiva de inclusão na assistência prestada dentro das SR aos alunos provenientes das séries iniciais $\left(1^{\mathrm{a}}\right.$ a $\left.4^{\mathrm{a}}\right)$ do ensino fundamental, evidenciados por meio do acompanhamento realizado pela escola, da comunicação existente entre os profissionais de SR e ensino comum e dos materiais pedagógicos utilizados, com destaque para as atividades lúdicas. No entanto, apesar da grande variedade de NEEs atendidas, ficou explícita a dificuldade no processo de ensino-aprendizagem que esses profissionais enfrentam. Embora o município apresente um serviço educacional especializado bem estruturado, nas escolas municipais, para atendimento das NEEs, ainda são necessárias algumas modificaçóes estratégicas para melhor atender esses alunos.

Palavras-chave: Educação Especial; Sala de recurso; Inclusão educacional.

\footnotetext{
* Professora doutora da Universidade Estadual do Oeste do Paraná. Foz do Iguaçu, Paraná, Brasil.

** Enfermeiro do Hospital Municipal Padre Germano Lauck. Foz do Iguaçu, Paraná, Brasil.

*** Professora da Universidade Estadual do Oeste do Paraná. Foz do Iguaçu, Paraná, Brasil.

**** Professor doutor da Universidade Estadual do Oeste do Paraná. Foz do Iguaçu, Paraná, Brasil.

***** Professora doutora da Universidade Estadual do Oeste do Paraná. Foz do Iguaçu, Paraná, Brasil.

****** Professora da Universidade Estadual do Oeste do Paraná. Foz do Iguaçu, Paraná, Brasil.
} 


\section{Teachers' perception in resource rooms on a network teaching of Paraná}

\section{Abstract}

This research analyzed the perception of the teacher who works in resource rooms (SR) in public primary schools in Foz do Iguaçu/PR, about the school inclusion of NEE's students. It's a quantitative and qualitative research, using the technique of Collective Subject Speech (DSC). The data were collected in 2012's first semester, through questionnaires answered by public primary school teachers. The results were organized in worksheets for descriptive analysis of speech. A well structured service was identified, showing a great concern at the public policies level about the inclusion's perspective in the assistance provided in the SR to students from the lower grades (1st to 4th) of elementary education, evidenced through the monitoring conducted by the school, the existent communication between the SR professionals and the regular education and the use of teaching materials, highlighting the ludic activities. However, in spite of the great variety of the attended NEEs, it was explicit the difficulty in the teaching process that these professionals face. Though the Municipality shows a well structured educational service in public primary school for seeing NEEs, it's still necessary some strategic modification to better attend these students.

Keywords: Special Education; Resource Room; Educational Inclusion.

\section{Introdução}

Entende-se por Educação Especial um conjunto de medidas e recursos (humanos e materiais) colocados à disposição de alunos com necessidades educativas especiais, os quais portam algum tipo de deficiência/necessidades educacionais especiais (NEEs), como: deficiência sensorial (auditiva ou visual), motora e cognitiva, altas habilidades/superdotação, transtornos psicomotores, doenças crônicas, transtornos de personalidade, autismo, psicoses, Síndrome de Down, deficiências múltiplas, inadaptação social e dependência química, que podem ser temporárias ou permanentes (UNESCO, 1998; KOEHLER, 2008).

Percebe-se que a Educação Especial é abrangente e engloba uma diversidade de necessidades educativas. A educação inclusiva é um movimento de ação política, social, cultural e pedagógica em defesa dos direitos de todos, sem nenhum tipo de discriminação e ao encontro do paradigma educacional em que igualdade e diferença são indissociáveis (BRASIL, 2007), o que consiste em incluir em escolas regulares, aos seus respectivos níveis, aqueles alunos que apresentam alguma deficiência na vida educativa e social (MOREIRA, CASTRO, SANT'ANA, 2004).

A educação especial, em âmbito nacional, restringe-se quase que exclusivamente ao processo de inclusão dos alunos que apresentam algum tipo de deficiência/ NEEs. No entanto, há uma contribuição para produçáo de conhecimento e pesquisa de diferentes autores relacionados com a educação especial em geral (BUENO, 
1999; GLAT, BLANCO, 2007; OLIVEIRA, 2007; PLETSCH, 2009). Em 1994, a Declaraçâo de Salamanca proclama que as escolas regulares, com orientação inclusiva, constituem os meios mais eficazes de combater atitudes discriminatórias e que alunos com necessidades educacionais especiais devem ter acesso à escola regular, tendo como princípio orientador que "as escolas deveriam acomodar todas as crianças independentemente de suas condições físicas, intelectuais, sociais, emocionais, linguísticas ou outras" (BRASIL, 2006). Uma das inovaçôes trazidas pela Política Nacional de Educação Especial na Perspectiva da Educação Inclusiva, em 2007, é o Atendimento Educacional Especializado (AEE), um serviço da educação especial que "[...] identifica, elabora e organiza recursos pedagógicos e de acessibilidade, que eliminem as barreiras para a plena participação dos alunos, considerando suas necessidades específicas" (BRASIL 2008).

De acordo com as Diretrizes Operacionais da Educação Especial para o Atendimento Educacional Especializado na Educação Básica, publicada pela Secretaria de Educação Especial - SEESP/MEC, em abril de 2009, o Projeto Político Pedagógico da Escola deve contemplar o atendimento para a educação especial. Nesse sentido, é preciso planejar, organizar, executar e acompanhar os objetivos, metas e açóes traçadas, em articulação com as demais propostas da escola comum (BRASIL, 2009).

Em 2004, o estado do Paraná obteve uma conquista significativa, com a inserção da sala de recurso (SR) na rede estadual do $6^{\circ}$ a $9^{\circ}$ ano para o atendimento de alunos com deficiência mental/intelectual; altas habilidades/superdotação; transtornos funcionais específicos ou transtornos globais do desenvolvimento (BERTUOL, 2010). O serviço já era disponibilizado para os alunos provenientes das séries iniciais (1a à $4^{a}$ séries) do Ensino Fundamental, e foi por meio da instruçáo 013/08- SUED/ SEED que se estabeleceram alguns critérios para o seu funcionamento perante o atendimento aos alunos com deficiência mental/intelectual e/ou transtornos funcionais específicos (distúrbios de aprendizagem: dislexia, disgrafia, discalculia, disortografia; transtorno de atenção e hiperatividade), assegurando ao aluno a participaçáo no ingresso, acompanhamento e avaliação no ensino regular em contraturno no sistema municipal de ensino no estado do Paraná (PARANÁ, 2008).

A avaliação para o ingresso do aluno depende de uma atuação em conjunto do professor do ensino regular, do especialista, do pedagogo, da equipe multiprofissional externa e da equipe do Núcleo Regional de Educação (NRE). Já a avaliação referente ao desempenho do aluno dependerá da NEEs apresentada, a qual abrange aspectos pedagógicos relativos à leitura, à escrita, à interpretação e à produção de textos, aos cálculos matemáticos e outros a pedido do parecer do psiquiatra e/ou neurologista e complementadas, também, por um psicólogo (PARANÁ, 2008).

Embasado na deliberação N. 02/03-CEE, art. 33 e 34, o professor da SR deverá possuir especialização em cursos de pós-graduação em Educação ou licenciatura plena com habilitação em Educação Especial ou habilitação específica em nível médio, na extinta modalidade de estudos adicionais e, atualmente, na modalidade normal (PARANÁ, 2008). No entanto, o que se observa, empiricamente, são professores não adequadamente capacitados para o desenvolvimento dessas atividades, dificul- 
tando, assim, o atendimento educacional especializado (AEE). Outro dado relevante é o remanejamento de alunos para a SR no momento em que estes não acompanham o ritmo dos demais colegas da turma, o que é contraditório aos critérios estabelecidos de uma avaliação multiprofissional e que causa abarrotamento de alunos no apoio especializado (ROCHA, 2009).

Diante desse contexto, nos últimos anos, a escola se tornou palco de muitos fracassos ou desenvolvimentos insatisfatórios e precários. Entretanto, com o trabalho do professor aliado ao AEE, por meio de jogos, brincadeiras, materiais didáticos e processos pedagógicos, esse paradigma pode se reverter e permitir ao aluno a capacidade de acompanhar o restante da turma, dentro do ensino regular (OLIVEIRA, 2011). Destarte, esta pesquisa teve como objetivo identificar e discutir a percepçáo que o professor da sala de recursos possui sobre o processo de inclusão dos alunos com deficiência/NEEs, nas escolas municipais de Foz do Iguaçu/PR.

\section{Métodos}

O trabalho de pesquisa foi desenvolvido sob a forma quantiqualitativa, tratando-se de um estudo transversal, realizado nas escolas municipais de Foz do Iguaçu/PR, localizada no extremo oeste do Paraná, reconhecida como regiáo de tríplice fronteira, pois faz fronteira com Paraguai e Argentina, de modo que tem relevante papel no estado e no país. Possui área total de $617,7 \mathrm{~km} 2$, sendo a quarta cidade mais populosa do Estado (estimativa de 263.508 habitantes), com uma população de adolescentes estimada em 46.962 habitantes (IBGE, 2010). Outra particularidade é abrigar aproximadamente 72 nacionalidades das 192 existentes no mundo. Conta com uma rede de ensino onde estão incluídas as SR, com trinta profissionais atuando em vinte e sete escolas públicas e em trinta e oito turmas.

A coleta de dados ocorreu por meio de um questionário semiestruturado, contendo 15 questóes de caráter quantitativo (versando sobre aspectos socioeconômicos dos professores e perfil epidemiológico do atendimento na SR), e três de caráter qualitativo, sobre o funcionamento das SR. Tais questóes foram analisadas pela técnica do Discurso do Sujeito Coletivo (DSC), tendo em vista que, conforme Lefevre, Lefevre, Teixeira (2000), discurso é uma ideia, opiniáo ou algo que as pessoas emitem em conjunto. A coleta de dados ocorreu no primeiro semestre de 2012.

As questóes qualitativas foram analisadas extraindo-se de cada depoimento as Expressóes-Chave $(\mathrm{ECH})$, sintetizando-as de acordo com a semelhança entre a Ideia Central (IC) de cada uma delas (LEFREVE, LEFREVE, TEIXEIRA, 2000). Para a análise dos depoimentos coletados e a construção dos DSCs, utilizou-se o instrumento de análise do discurso (IAD) - criado por Lefevre e Lefevre (2003).

Os dados quantitativos foram tabulados no Microsoft Excel ${ }^{\bullet}$, analisados segundo as porcentagens e representados por meio de tabelas, permitindo uma análise precisa, clara e objetiva dos dados. Obteve-se autorização da Secretaria Municipal de Educação do Município de Foz do Iguaçu/PR e aprovação do Comitê de Ética em Pesquisa em Seres Humanos (CONEP) da Universidade Estadual do Oeste do Paraná - UNIOESTE, sob parecer número 1447/2011. 
A coleta de dados foi conduzida após o professor receber informações acerca deste estudo, aceitar participar e assinar o Termo de Consentimento Livre Esclarecido (TCLE). Os dados obtidos nos questionários foram utilizados, unicamente, para fins de pesquisa.

\section{Resultados}

Foram entrevistados todos os trinta professores responsáveis pelas SR, todos do sexo feminino, atuando em 38 turmas de SR, nas 27 escolas municipais de ensino de Foz do Iguaçu/PR, no ano de 2012. O grupo de professoras que participou da pesquisa obteve uma média de idade de 45 anos e um tempo médio de atuaçáo na docência de 21,53 anos, todas com curso superior e pós-graduação em nível de especialização, sendo que 24 (80\%) delas possuíam alguma especialização intitulada "Educação Especial" (Tabela 1).

Quanto ao número de alunos por turma, 19 docentes (63,33\%) possuíam, em média, 21 a 30 alunos; 20 docentes $(66,66 \%)$ relataram que não desempenhavam nenhuma outra atividade a não ser a executada dentro da SR e 25 (83,33\%) trabalhavam somente em uma escola. Das dez professoras (33,33\%) que afirmaram exercer outra atividade, apenas cinco especificaram quais eram essas atividades (apoio permanente a um deficiente físico, atividade de coral e musicalizaçáo na escola, uma é arquiteta, uma é pedagoga e uma atua como professora no ensino regular).

Quando questionadas se acreditavam estar capacitadas profissionalmente para trabalhar com crianças (NEEs), 24 (80\%) das entrevistadas consideraram-se aptas. Em relação ao processo de inclusão relacionando a SR e sala de ensino comum, 19 $(63,33)$ das entrevistadas concordaram que as crianças com NEEs devem estar inseridas na sala de aula regular. E salienta-se que o atendimento da SR foi mensurado por 17 sujeitos $(56,66 \%)$ como ótimo.

Tabela 1 - Caracterização dos professores das escolas municipais de Foz do Iguaçu/PR, quanto ao atendimento e à inclusão de alunos com deficiência/NEEs. Foz do Iguaçu, 2012.

\begin{tabular}{ccccccc}
\hline Variáveis & n. & $\%$ & Variáveis & n. & $\%$ \\
\hline Sexo & & \multicolumn{5}{c}{ Inclusáo alunos SR } \\
Feminino & 30 & 100 & Concordam & 19 & 63,3 \\
Masculino & --- & --- & Discordam & 05 & 16,7 \\
& & & S/ resposta & 06 & 20,0 \\
Qualidade atendimento na & & & Alunos por turma & & \\
SR & & & Até 20 & 06 & 20,0 \\
Ótimo & 17 & 56,7 & 21 a 30 & 19 & 63,3 \\
Bom & 12 & 40,0 & 31 a 40 & 05 & 16,7 \\
Regular & 01 & 03,3 & &
\end{tabular}


Adriana Zilly - Leonardo Pereira Triaca - Jossiana Wilke Faller - Reinaldo Antonio da Silva Sobrinho Marieta Fernandes Santos - Maria de Lourdes de Almeida

Continuação Tabela 1

Esp. Ed. Especial

$\begin{array}{lll}\text { Sim } & 24 & 80,0 \\ \text { Não } & 06 & 20,0\end{array}$

\section{Único emprego}

Sim

Não

\section{Sentem-se Capacitados}

$\begin{array}{lll}\text { Sim } & 24 & 80,0 \\ \text { Não } & 06 & 20,0\end{array}$

Exerce outra atividade

Sim $\quad 10 \quad 33,3$

S/: Sem; Esp.: especializaçăo; Ed.: Educaçấo; N.: Número da amostragem. Fonte: Dados da pesquisa. Foz do Iguaçu-PR, 2012.

No concernente à participação da escola no acompanhamento das atividades desenvolvidas na SR, 26 professores (86,66\%) responderam ter esse acompanhamento, que acontecia de forma periódica, por meio de apoio e orientação da supervisão em forma de relatórios; termos de responsabilidade; observaçáo das atividades; investigação da frequência e caderno dos alunos; visitas da equipe pedagógica composta por uma equipe multidisciplinar (psicóloga, fonoaudióloga e assistente social), além da troca de informação entre os professores.

Quanto ao questionamento: "Você acredita ser necessário o acompanhamento dessas crianças por um profissional da área da saúde?”, 29 (96,66\%) responderam afirmativamente. No que tange aos argumentos sobre quais eram as atividades desenvolvidas na SR para os alunos com NEEs, houve uma gama de respostas de caráter discursivo que foram avaliadas de acordo com a metodologia do DSC. Os dados possibilitaram a formação de cinco DSCs (Quadro 1): 


\begin{tabular}{|c|c|}
\hline Ideais Centrais & Discurso do Sujeito Coletivo \\
\hline IC A & DSC A \\
\hline $\begin{array}{l}\text { Realizo atividades para } \\
\text { elevar a autoestima e } \\
\text { permitir a socialização. }\end{array}$ & $\begin{array}{l}\text { Eu trabalho com dinâmicas, brincadeiras e atividades que são } \\
\text { feitas para o desenvolvimento da socialização, relaxamento e para } \\
\text { elevar a autoestima. }\end{array}$ \\
\hline $\mathrm{IC} \mathrm{B}$ & DSC B \\
\hline $\begin{array}{l}\text { Eu trabalho o } \\
\text { conteúdo de maneira } \\
\text { lúdica e prazerosa. }\end{array}$ & $\begin{array}{l}\text { Eu trabalho as mesmas matérias da sala regular, porém de } \\
\text { formas diferenciadas. O conteúdo é reforçado de maneira lúdica } \\
\text { e prazerosa para o desenvolvimento do raciocínio, atençáo e } \\
\text { concentração motora, atividades de desenvolvimento cognitivo, } \\
\text { de memorização/atenção/concentração, de percepçáo visual, } \\
\text { lateralidade, esquema corporal, coordenação global, memória } \\
\text { visual, auditiva, desenvolvimento de inteligências múltiplas. } \\
\text { São realizadas atividades psicomotoras com jogos intelectuais } \\
\text { e educativos e todas as brincadeiras com jogo individualizado } \\
\text { por aluno com material concreto de apoio, cada um na sua } \\
\text { dificuldade. Assim trabalho: sequência de frases (dominó), } \\
\text { tabuada, operaçóes (dominó), lógica, computaçáo com jogos, } \\
\text { dominós associativos, ortografia, jogos pedagógicos, formação } \\
\text { de palavras, alfabeto móvel, massinha, caça-palavras, construção } \\
\text { de alguns jogos infantis, diagramas, quebra-cabeças, coordenaçáo } \\
\text { motora fina com dobraduras e artesanato, alinhavo, atividades de } \\
\text { artes com recortes, costura, pintura, colagens e diversos métodos } \\
\text { que reforçam os conteúdos trabalhados. }\end{array}$ \\
\hline IC C & DSC C \\
\hline $\begin{array}{l}\text { Eu realizo atividades } \\
\text { sobre os conteúdos } \\
\text { que se encontram em } \\
\text { defasagem. }\end{array}$ & $\begin{array}{l}\text { Eu realizo atividades de alfabetização, interpretação oral, treino da } \\
\text { escrita, interpretaçáo de problemas, raciocínio lógico e contagem, } \\
\text { problematização, gincanas, operaçôes, desenvolvimento da } \\
\text { leitura variada através de palavras, frases e textos de livros e } \\
\text { gibis (realizada pela professora ou por eles mesmos), oralidade, } \\
\text { consistência fonológica. São desenvolvidas com muito prazer } \\
\text { sobre os conteúdos que se encontram em defasagem. }\end{array}$ \\
\hline $\mathrm{ICC} D$ & DSC D \\
\hline $\begin{array}{l}\text { Trabalho o } \\
\text { relaxamento e } \\
\text { reflexão através } \\
\text { da dramatização e } \\
\text { musicalidade. }\end{array}$ & $\begin{array}{l}\text { Eu trabalho relaxamento e reflexão, com poemas, brincadeiras, } \\
\text { teatro de fantoches, recortes de histórias para dramatização ou } \\
\text { reescrita em resumo para reestruturação dos mesmos, filmes, } \\
\text { conversas informais, contar relato pessoal, trabalhos com músicas } \\
\text { (ritmo, instrumentos musicais, dança). }\end{array}$ \\
\hline
\end{tabular}


Adriana Zilly - Leonardo Pereira Triaca - Jossiana Wilke Faller - Reinaldo Antonio da Silva Sobrinho Marieta Fernandes Santos - Maria de Lourdes de Almeida

Continuação quadro 1

\begin{tabular}{|l|l|}
\hline \multicolumn{1}{|c|}{ IC E } & \multicolumn{1}{|c|}{ DSC E } \\
Realizo atividades & Uso as tecnologias assistivas (minutos de informática) dando o \\
no computador para & suporte pedagógico necessário, para que o aluno permaneça \\
desenvolvimento da & no ensino regular. São desenvolvidas atividades interativas \\
aprendizagem. & no computador com pesquisas e jogos direcionados para o \\
& desenvolvimento da aprendizagem. \\
\hline
\end{tabular}

Quadro 1: Apresentaçáo das Ideias Centrais e Discursos do Sujeito Coletivo sobre atividades desenvolvidas nas SRs do sistema municipal de ensino em Foz do Iguaçu/PR, 2012.

Em relação ao contato estabelecido entre os professores das SR e do ensino regular, para discussão sobre os alunos, cuja responsabilidade é de ambos, emergiram quatro IC, reveladas no quadro 2.

\begin{tabular}{|c|c|}
\hline Ideais Centrais & Discurso do Sujeito Coletivo \\
\hline $\begin{array}{l}\text { IC A } \\
\text { Eu mantenho contato } \\
\text { constantemente, pois } \\
\text { os alunos frequentam } \\
\text { a sala de recursos e a } \\
\text { turma regular nessa } \\
\text { mesma escola. }\end{array}$ & $\begin{array}{l}\text { DSC A } \\
\text { Eu trabalho com alunos da sala de recurso e turma regular na } \\
\text { escola, isso ajuda, fica mais fácil, pois o contato é feito direto } \\
\text { com o professor nos intervalos quando necessário, onde trocamos } \\
\text { informaçóes e olho os cadernos do ensino regular, assim estou } \\
\text { constantemente conversando entre eles. As conversas são } \\
\text { frequentes, quase que diariamente, ouvindo queixas ou sujestôes } \\
\text { sobre os mesmos, ou nas sextas-feiras, o dia do planejamento } \\
\text { semanal, busco contato com os professores que trabalham com } \\
\text { os alunos que atendo. }\end{array}$ \\
\hline $\begin{array}{l}\text { IC B } \\
\text { Eu faço visitas nas } \\
\text { sextas-feiras durante } \\
\text { o período da hora- } \\
\text { atividade, realizando } \\
\text { o contato com os } \\
\text { professores de alunos } \\
\text { que náo frequentam } \\
\text { ensino regular em } \\
\text { nossa escola. }\end{array}$ & $\begin{array}{l}\text { DSC B } \\
\text { Eu faço visitas ao professor do ensino regular dos alunos que não } \\
\text { frequentam em nossa escola, por isso conversamos diretamente } \\
\text { para saber o desempenho de cada um e discutir o rendimento } \\
\text { escolar da aula em questáo identificando barreiras ou limitaçóes } \\
\text { que possa estar vivenciando, e reatamos o que já deu certo e o que } \\
\text { é preciso melhorar para que eu possa trabalhar e principalmente } \\
\text { para preenchimento de relatórios onde é proposto um trabalho } \\
\text { colaborativo com o regente de classe comum para troca de } \\
\text { informaçóes. Esse contato é feito periodicamente através de } \\
\text { encontros em outras escolas, semanalmente ou mensal, ou sempre } \\
\text { que possível, é chamado "trabalho itinerante" para conversar com } \\
\text { professores e também supervisores de origem, trocando ideias a } \\
\text { respeito dos avanços, ou não, dos atendidos e acompanhamento } \\
\text { do desenvolvimento das necessidades particulares pedagógicas. }\end{array}$ \\
\hline
\end{tabular}


Continuação quadro 2

\begin{tabular}{|l|l|}
\hline \multicolumn{1}{|c|}{ IC C } & \multicolumn{1}{c|}{ DSC C } \\
\hline $\begin{array}{l}\text { Eu faço contato } \\
\text { geralmente durante a } \\
\text { hora-atividade. }\end{array}$ & $\begin{array}{l}\text { Eu geralmente faço durante a hora-atividade, uma vez por semana, } \\
\text { ou seja, no dia em que é feito o planejamento necessário para } \\
\text { melhorar o desenvolvimento escolar. É marcado um horário, } \\
\text { sendo o tempo disponível para comentar sobre o desenvolvimento } \\
\text { ou as dificuldades, também troca de informaçóes entre os dois } \\
\text { professores sobre determinado aluno e recursos. }\end{array}$ \\
\hline $\begin{array}{l}\text { IC D } \\
\text { Eu mantenho contatos } \\
\text { esporádicos com os } \\
\text { professores do ensino } \\
\text { regular. }\end{array}$ & $\begin{array}{l}\text { Eu e os professores do ensino regular mantemos contatos } \\
\text { esporádicos. Na hora do lanche, antes da aula quando surge alguma } \\
\text { dúvida/progressos ou qualquer outra situação de necessidade e, } \\
\text { também com a supervisão e direçáo da escola quando acontece } \\
\text { algo de urgente, usamos contato por telefone nos casos de faltas } \\
\text { ou outros problemas que precisam ser solucionados o mais rápido } \\
\text { possível. As conversas acontecem com trocas de informaçóes em } \\
\text { todo momento onde me pedem algo ou vou até eles para falar da } \\
\text { evoluçáo ou náo do aluno, sendo um trabalho de muita interaçáo } \\
\text { sempre que necessário. }\end{array}$ \\
\hline
\end{tabular}

Quadro 2. Apresentação das Ideias Centrais e Discursos do Sujeito Coletivo sobre contato entre o professor(a) da SR com o do ensino regular do sistema municipal de ensino em Foz do Iguaçu/PR, 2012.

No tocante às prevalências das NEEs dentro da SR e à dificuldade sobre o aprendizado, surgiram as seguintes IC e DSCs, descritas no quadro 3:

\begin{tabular}{|c|c|}
\hline Ideias Centrais & Discurso do Sujeito Coletivo \\
\hline IC A & DSC A \\
\hline $\begin{array}{l}\text { Eu atendo alunos com } \\
\text { diagnósticos diversificados } \\
\text { que dificultam o processo de } \\
\text { ensino-aprendizagem. }\end{array}$ & $\begin{array}{l}\text { Atendo alunos com transtornos funcionais específicos } \\
\text { (dislexia, disortografia, disgrafia, discalculia e TDAH), } \\
\text { transtorno global do desenvolvimento (autismo: Síndrome } \\
\text { de Asperger, de Rett e desintegrativo da infância), } \\
\text { deficiência física, auditiva, visual, mental (leve e moderada) } \\
\text { e intelectual, até alguns com distúrbio de comportamento } \\
\text { (depressáo, agressividade e irritabilidade), transtorno } \\
\text { bipolar e esquizofrenia. A maioria dos alunos apresenta } \\
\text { dificuldades no processo de aprendizagem, memorizaçáo, } \\
\text { raciocínio lógico dos conhecimentos matemáticos, leitura } \\
\text { (em perceber erros associados a condutas típicas sem } \\
\text { exclusividade, como o déficit de atenção, a hiperatividade, } \\
\text { o desinteresse e falta de compromisso, ironia, raciocínio } \\
\text { lento e defasagem dos conteúdos apresentados. }\end{array}$ \\
\hline
\end{tabular}


Adriana Zilly - Leonardo Pereira Triaca - Jossiana Wilke Faller - Reinaldo Antonio da Silva Sobrinho Marieta Fernandes Santos - Maria de Lourdes de Almeida

Continuação quadro 3

\begin{tabular}{|c|c|}
\hline IC B & DSC B \\
\hline $\begin{array}{l}\text { A Deficiência Mental, os } \\
\text { Transtornos Funcionais } \\
\text { Específicos e os Distúrbios } \\
\text { de Comportamento são as } \\
\text { NEEs que apresentam maior } \\
\text { dificuldade de aprendizado. }\end{array}$ & $\begin{array}{l}\text { As crianças com maior dificuldade de aprendizado são as } \\
\text { que apresentam deficiência mental, transtornos funcionais } \\
\text { específicos (Déficit de atenção e hiperatividade) e } \\
\text { distúrbio de comportamento (bipolares). Sáo muito } \\
\text { agitados e de difícil concentração e percepçáo, autoestima } \\
\text { baixa, agressivos e inquietos, principalmente quando } \\
\text { contrariados ou cobrados, tornando difícil o atendimento } \\
\text { desses portadores. }\end{array}$ \\
\hline
\end{tabular}

Quadro 3. Apresentação das Ideias Centrais e Discursos do Sujeito Coletivo sobre a prevalência das NEEs dentro da SR e a dificuldade sobre o aprendizado. Foz do Iguaçu/PR, 2012.

\section{Discussão}

O fato de todos os profissionais possuírem pós-graduação em nível de especialização cumpre com o requisito exigido na Instrução N. 013/08- SUED/SEED, embasada na Deliberação no 02/03-CEE, art. 33 e 34, de que um dos requisitos para atuação perante as SR é especialização em cursos de Pós-Graduação em Educação Especial (PARANÁ, 2008). Para que o professor consiga superar os obstáculos em sua carreira como educador, seu perfil deve ser construído com ênfase na formação acadêmica, a qual se torna essencial para o gerenciamento e a avaliação dos alunos (SILVA, 2006).

Ante a qualificaçáo apresentada pela maioria dos professores (especialização em Educação Especial), ainda verificou-se a preocupação existente por parte destes em se atualizar para atuar na SR. É necessário que o professor saiba lidar com uma diversidade de NEEs, sendo um fator determinante para atender a cada criança. Para Mantoan (2003), a criança deve ser acolhida de acordo com suas potencialidades para que possa ser inserida na sociedade. Deste modo, a educação inclusiva é considerada de fundamental importância para a reinserção da criança no meio social. Na busca de melhoria do serviço prestado, muitos profissionais almejam implantação de mudanças em suas práticas pedagógicas (SANT'ANA, 2005) e pelo fato de a maioria trabalhar em apenas uma escola, acredita-se que a dedicação e o cuidado para com os alunos com NEEs devem ser maiores.

Cada turma é dividida em dois grupos por período, cada um com tempo de duas horas diárias, o que está de acordo com a Instrução N. 013/08- SUED/SEED, com número máximo de vinte alunos por cronograma, ou seja, dez alunos a cada duas horas (PARANÁ, 2008). O atendimento deve ser feito de forma individualizada ou em grupo, sempre com ênfase ao trabalho individual. Para melhor aproveitamento, os alunos devem ser classificados por necessidades pedagógicas ou, até mesmo, por faixa etária (BERTUOL, 2010).

$\mathrm{O}$ aluno tem por direito frequentar a SR até que suas dificuldades sejam cessadas e consiga obter êxito no processo de ensino-aprendizagem dentro da sala de ensino comum, além de frequentar o ensino regular em outros estabelecimentos, desde que apresente a documentação necessária. Faz-se importante salientar que o trabalho 
dentro da SR não deve ser confundido com reforço escolar, repetindo-se o conteúdo que já lhe foi passado em classe comum (PARANÁ, 2008). Tessaro (2007) acredita que incluir alunos com Deficiência/NEEs no ensino regular é totalmente viável desde que para isso aconteçam investimentos e comprometimento em nível de políticas públicas dos órgãos governamentais, respeitando-se a complexidade de tal processo. Isso representa um avanço considerável na história da Educação, principalmente em relação ao movimento de inclusão.

Os professores relataram a existência de materiais pedagógicos dentro da sala, por eles confeccionados ou adquiridos com recursos da Secretaria de Educação, como, por exemplo, jogos (quebra-cabeça, dominó), livros diversos, computadores (software especializado), TV, DVD e instrumentos especializados (alfabeto móvel, réguas numéricas, ábaco etc.). Estudos, realizados anteriormente em alguns municípios brasileiros, já destacaram a importância desse serviço especializado em apoio ao estudante com NEEs que frequenta o ensino comum (BAPTISTA, 2011).

Acredita-se que a mediação e o uso de jogos são fatores fundamentais inerentes à formação do aluno e que facilitam o processo de ensino-aprendizagem, sendo os jogos responsáveis pelo desenvolvimento cognitivo, motor, intelectual e moral. Ao mesmo tempo em que o brinquedo passa a ser uma atividade e com ela uma conexão geradora de mudança no desenvolvimento psíquico da criança, que, ao desenvolvê-la, as prepara para estágios de desenvolvimento mais elevado (GHEDIN, 2012). Para a utilização desses recursos, é fundamental o comprometimento desses especialistas, o que contribui tanto para a aprendizagem dos alunos como para atribuir créditos ao seu próprio trabalho (BERTUOL, 2010).

Tem-se que o trabalho da SR não depende somente do professor especialista, mas também da equipe multidisciplinar para identificar o diagnóstico do aluno e encaminhá-lo ao AEE, a qual inclui a equipe pedagógica durante as avaliaçóes, metodologias e adaptaçóes curriculares e da escola, ficando sob sua responsabilidade a supervisão das atividades desenvolvidas dentro da SR e a manutenção da documentação dos alunos (BERTUOL, 2010), pois a escola tem o dever de prezar pela boa formação de seus cidadãos, independentemente das diferenças (MEZZAROBA; NAGAO, 2008).

Em relação à saúde e à educação, estas sempre foram áreas inseparáveis, principalmente no que se refere ao apoio a indivíduos com Deficiência/NEEs, uma vez que a articulação entre ensino e saúde se torna critério básico para a promoção de vida saudável de escolares (GLAT et al., 2006). No estudo de Carvalho et al. (2002) sobre os portadores de visão subnormal dentro da SR, nessa perspectiva de inclusão, a escola e o professor têm desempenhado um importante papel de detectar as dificuldades dessas crianças e, portanto, a ausência de uma estrutura ou a falta de conhecimento dos profissionais podem prejudicar o desenvolvimento das potencialidades dos alunos.

$\mathrm{Na}$ maioria das escolas públicas brasileiras, os problemas responsáveis pela dificuldade de aprendizagem nem sempre são observados pelos professores. Entre os 
fatores possíveis para explicar esse fato encontram-se o número excessivo de alunos, as condiçôes precárias de trabalho e a falta de formação adequada dos profissionais (Santos et al., 2012), por isso, além de uma equipe multidisciplinar, é necessário traçar estratégias de atendimento integrado, envolver todos os profissionais da equipe, estabelecer prioridades para um melhor desempenho desses indivíduos e manter um diálogo entre saúde e educação (GLAT et al., 2006).

Para que a inclusão de crianças com deficiência ocorra de modo sensível às necessidades de todos os envolvidos no processo educativo, é necessário um ambiente que considere as relaçóes estabelecidas entre as pessoas, e não apenas as questôes estruturais (SILVA, LEME, 2009). Segundo a Organização Pan-americana de Saúde (OPS, 1995), a promoção da saúde no âmbito escolar parte de uma visão integral e multidisciplinar do ser humano, que considera as pessoas em seu contexto familiar, comunitário, social e ambiental. Assim, as açóes de promoção de saúde visam desenvolver conhecimentos, habilidades e destrezas para o autocuidado da saúde e a prevenção das condutas de risco em todas as oportunidades educativas; bem como fomentar uma análise sobre valores, condutas, condiçôes sociais e estilos de vida dos próprios sujeitos envolvidos (GONÇALVES et al., 2009).

Quanto à análise dos DSCs, os dados presentes na figura 1 sintetizam a mesma perspectiva da instrução no $013 / 08$ - SUED/SEED, determinando que o trabalho pedagógico a ser desenvolvido dentro da SR deve ser constituído de um conjunto de práticas e procedimentos individuais, de modo a desenvolver no aluno o processo motor, cognitivo, socioafetivo e emocional, de acordo com a necessidade de cada um e os conteúdos que se apresentam em defasagem, principalmente no que concerne às disciplinas de português e matemática (PARANÁ, 2008).

Os discursos da figura 2 demonstram a articulação preconizada para o acompanhamento pedagógico, ou seja, a troca de informaçôes sobre os alunos, inclusive a realização de orientaçôes por parte do professor da SR para com o do ensino comum sobre as informaçóes específicas de cada educando, permitindo que o aluno supere suas necessidades e tenha subsídios para acompanhar o desenvolvimento dos demais alunos da turma regular. Esse diálogo entre professores permite a intervenção frequente nas principais dificuldades apresentadas pelos alunos, resultando, diretamente, em um melhor desempenho destes (SILVA, 2006).

Assim, de acordo com Carvalho et al. (2002), o professor especialista, por meio de seus conhecimentos, deverá ser um elo para que, de maneira eficaz, proporcione ao restante dos professores do ensino regular informaçóes necessárias para trabalhar e enfrentar os obstáculos apresentados pelas diversidades encontradas. Segundo Ropoli et al. (2010), os professores do ensino regular e os da educação especial precisam se envolver para que seus objetivos específicos de ensino sejam alcançados, compartilhando um trabalho interdisciplinar e colaborativo. Cabe ainda ao professor do ensino regular o ensino das áreas do conhecimento, e ao professor da educaçáo especial complementar/suplementar a formaçáo do aluno com conhecimentos e recursos específicos que eliminam as barreiras, as quais impedem ou limitam sua participação com autonomia e independência. 
Para Honnef, Costas (2012), faz-se essencial que os processos de formação docente não desconsiderem as experiências pedagógicas dos professores, mas sim partam delas as discussôes, reflexôes e açôes realizadas no contexto escolar, pois a atenção ao aluno especial passa náo ser mais de responsabilidade exclusiva da educaçáo especial, mas sim, também do ensino comum.

Os discursos da figura 3 destacam a diversidade de NEEs atendidas e que não estão totalmente de acordo com o estabelecido pela Instrução No 013/08- SUED/ SEED, pois esta decide que o alunado deverá prioritariamente estar matriculado no ensino regular e apresentar Transtorno Funcional Específico (Distúrbios de aprendizagem: dislexia, disgrafia, discalculia, disortografia; Transtorno de atenção e hiperatividade) e/ou Deficiência Mental/Intelectual (PARANÁ, 2008).

Além disso, na IC do DSC "A" (Figura 3), a dificuldade do processo de ensino-aprendizagem verbalizada pelos professores é uma grande preocupação, a qual corrobora com outros estudos como, por exemplo, de Enumo (2005), quando afirma que crianças com NEEs geralmente enfrentam limitação da capacidade do aprender, ficando suscetíveis a desenvolver problemas psicológicos. Para Ghedin (2012), é importante conhecer como o sujeito organiza em sua estrutura cognitiva as informaçóes recebidas do meio. Cada ser é único e por isso percebe o ambiente de formas diferentes e dá a ele significados de acordo como o que percebe. Isto significa dizer que cada sujeito constrói o conhecimento de acordo como percebe e organiza as informaçóes em sua estrutura cognitiva, de modo que cabe ao professor possibilitar ao sujeito as oportunidades necessárias para a construçáo do processo de aprendizagem.

O DSC "B” (Figura 3) destaca que a Deficiência Mental/Transtorno Funcional Específico (distúrbios de aprendizagem) e os Distúrbios de Comportamento são as NEEs que apresentam maior dificuldade de aprendizado. No entanto, estas deficiências podem ser globais ou específicas. Por exemplo, a criança pode apresentar desenvolvimento físico normal e não falar, ou então, falar, andar, mas não conseguir aprender determinados conteúdos. Por isso, sempre merecem atenção no sentido de ajudá-las a superar, ressaltando que, quanto mais cedo esses déficits forem percebidos e diagnosticados, maior será a probabilidade de se evitar prejuízos e sofrimento para a criança e seus familiares. Com uma educaçáo adequada, uma criança pode aprender tudo o que for permitido por suas potencialidades, considerando seus limites, desenvolvendo-se o mais próximo da normalidade. Mesmo problemas de comportamento, agitação ou agressividade podem ter causas tratáveis e, com isso, melhoras e progresso (LEPRE, 2008).

Ainda, Del Prette, Barreto, Freitas (2011) afirmam que estudos sobre habilidades sociais têm mostrado que crianças com dificuldades de aprendizagem podem apresentar problemas de comportamento e vice-versa, também associado a ocorrência de déficits de habilidades sociais posteriormente.

Em relação aos alunos com Transtornos funcionais específicos, é importante que todos os envolvidos se empenhem em uma ação multidisciplinar, além da interação familiar, para que ocorra êxito nas açóes (FINK, FERRARI, CANAN, 2008). No estudo de Maria (2011), as crianças com dificuldade de aprendizagem e/ou deficiên- 
cia mental apresentam um melhor desempenho quando são ajudadas adequadamente por um suporte institucional especializado. De acordo com Teles, Resegue, Puccini (2013), qualquer julgamento da deficiência está sujeito a vieses de diferentes naturezas, sendo necessária a realizaçáo de avaliações multidisciplinares que possam oferecer informaçóes que contribuam para minimizar os aspectos excludentes e para que as ações envolvidas sejam mais efetivas.

Mediante a perspectiva da multidisciplinaridade, faz-se necessário superar tais dificuldades, de modo que se crie um ambiente favorável, por intermédio da utilizaçáo de jogos e brincadeiras, na tentativa de mediar os processos cognitivos e afetivos, para que os alunos com NEEs possam superar essas dificuldades e desenvolver suas potencialidades (OLIVEIRA, 2011). Deste modo, tanto a escola quanto os professores necessitam se reorganizar para melhor atender essas crianças, principalmente no que diz respeito à estrutura física e ao perfil dos profissionais em oferecer suporte adequado aos alunos (TEZZARI, BAPTISTA, 2009).

\section{Conclusões}

O perfil socioeconômico identificado demonstra que existe uma preocupação em nível de políticas públicas sobre a perspectiva da inclusão, o que fica evidente em relação à formaçáo dos professores, os quais, em sua totalidade, possuem pós-graduação, acreditando estar preparados para trabalhar com alunos portadores de NEEs e desempenhar suas atividades pedagógicas dentro da SR.

A atuação de um profissional da área da saúde, dentro da SR, torna-se indispensável, pois permite uma avaliaçáo rigorosa e detalhada desses alunos, favorecendo a detecçáo de fatores que possam influenciar, direta ou indiretamente, o aprendizado e tornar factível o diálogo entre saúde e educaçáo.

O acompanhamento, por parte da escola, nas atividades desenvolvidas dentro da SR, foi revelado e a troca de informaçóes entre professores da SR e do ensino comum, tấo preconizada pelos documentos legais, é realizada, pois, embora ocorra grande amplitude das açóes e a possibilidade interpretativa de práticas centradas no atendimento direto ao aluno, é necessário que se identifique a potencial valorização do trabalho compartilhado com outros profissionais, principalmente o docente do ensino regular, com o objetivo de discutir aspectos relevantes aos avanços ou dificuldades dos alunos, o que permite melhor desenvolvimento e continuidade ao processo de inclusão.

Os professores da SR demonstraram, por intermédio da análise do DSC, o enfrentamento de dificuldades no processo de ensino-aprendizagem dos alunos, sendo notória a necessidade de uma formação ampla e diversificada desses profissionais, para que possam superar os obstáculos do dia a dia, ante a grande variedade de NEEs que se apresentam.

Logo, a cidade de Foz do Iguaçu-PR apresenta um serviço educacional especializado bem estruturado nas escolas municipais para atendimento das NEEs, embora necessite de algumas modificaçóes estratégicas para melhor atender esses alunos, 
como incentivo e suporte para aprimoramento, por meio de cursos direcionados, e a inserção de um profissional da área da saúde, prioritariamente médico ou enfermeiro, em ação multidisciplinar com os demais, para avaliaçóes periódicas ao público, o que resultaria em um serviço de melhor qualidade.

\section{Referências}

BAPTISTA, C. R. Ação pedagógica e educação especial: a sala de recursos como prioridade na oferta de serviços especializados. Revista. Brasileira de Educaçáo Especial, v. 17, n. spe 1, p. 59-76. 2011.

BERTUOL, C. Salas de recursos e salas de recursos multifuncionais: apoio especializado a inclusâo escolar de alunos com deficiência/necessidades educativas especiais no município de Cascavel - PR. 2010, 58 f. Monografia (Especialista em História da Educação Brasileira) - Universidade Estadual do Oeste do Paraná, Cascavel, 2010 .

BRASIL. Ministério da Educação. Secretaria de Educação Especial. Direito à educaçáo: subsídios para a gestão dos sistemas educacionais - orientaçốes gerais e marcos legais. Brasília: MEC/SEESP, 2006.

BRASIL. Ministério da Educação. Conselho Nacional de Educação. Formaçáo continuada a distância de professores para o atendimento educacional especializado. Brasília. 2007.

BRASIL. Ministério da Educação. Secretaria de Educação Especial. Política Nacional de Educação Especial na Perspectiva da Educação Inclusiva. Inclusão: revista da Educação Especial, Brasília: MEC/SEESP, v. 4, n 1, jan./jun. 2008.

BRASIL. Ministério da Educação. Secretaria de Educação Especial. Diretrizes operacionais da Educaçáo Especial para o atendimento educacional especializado na educaçáo básica. Brasília: MEC/SEESP, 2009.

BUENO, J. G. S. Crianças com necessidades educativas especiais, política educacional e a formação de professores: generalistas ou especialistas? Revista Brasileira de Educaçáo Especial, v. 3, n. 5, p. 07-25. 1999.

CARVALHO, K. M. M. et al. Avaliação e conduta em escolares portadores de visão subnormal atendidos em sala de recursos. Arquivo Brasileiro de Oftalmologia, São Paulo, v. 65, n.4, p. 445-449, jul./ago. 2002.

DEL PRETTE, Z. A. P.; BARRETO, S. O.; FREITAS, L. C. Habilidades sociais na comorbidade entre dificuldades de aprendizagem e problemas de comportamento: uma avaliação multimodal. Psico, v. 42, n. 4, p. 503-510, 2011.

ENUMO, S. R. F. Avaliação assistida para crianças com necessidades educacionais especiais: um recurso auxiliar na inclusão escolar. Revista brasileira de Educaçáo Especial, v. 11, n. 3, p. 335-354. 2005.

FINK, A. T; FERRARI, R. F; CANAN, S. R. (Org.). Psicopedagogia em debate: série pesquisa em ciências humanas. 134 p. Universidade Regional Integrada do Alto Uruguai e das Missóes, Frederico Westphalen. 2008.

GHEDIN, E. Teorias psicopedagógicas do ensino aprendizagem. Boa Vista: UERR Editora, 2012.

GLAT, R. et al. Educaçáo e saúde no atendimento integral e promoção da qualidade de vida de pessoas com deficiências. Revista Linhas, v. 7, n. 2, p. 1-17, 2006.

GLAT, R.; BLANCO, L. Educação especial no contexto da educação inclusiva. In: GLAT, R. (Org.). Educaçáo inclusiva: cultura e cotidiano escolar. Rio de Janeiro: 7 LETRAS, 2007.

GONÇALVES, F. D. et al. A promoçấo da saúde na educaçấo infantil. Interface (Botucatu) - Comunicaçáo Saúde Educaçáo. v.12, n.24, p.181-92, 2009.

HONNEF, C.; COSTAS, F. A. T. Formação para a educaçáo especial na perspectiva inclusiva: o papel das experiências pedagógicas docentes nesse processo. Revista Reflexão e Ação, Santa Cruz do Sul, v. 20, n. 1, p. 111-124, jan./jun. 2012.

IBGE. Contagem populacional: censo demográfico 2010. Brasília, DF. Disponível em: <www.ibge.org.br>. Acesso em: 02 dez. 2013.

KOEHLER, L. C. Educação especial: da teoria à prática. ATHENA: Revista Científica de Educação, v. 11, n. 11, p. 54-59, jul/dez. 2008.

LEFEVRE, F.; LEFEVRE, A.M.C; TEIXEIRA, J. J. V. O discurso do sujeito coletivo: uma nova abordagem metodológica em pesquisa qualitativa. Caxias do Sul: EDUCS, 2000. 
Adriana Zilly - Leonardo Pereira Triaca - Jossiana Wilke Faller - Reinaldo Antonio da Silva Sobrinho Marieta Fernandes Santos - Maria de Lourdes de Almeida

LEFEVRE, F.; LEFEVRE, A.M.C. O discurso do sujeito coletivo: um novo enfoque em pesquisa qualitativa (desdobramentos). Caxias do Sul: EDUCS, 2003.

LEPRE, R. M. Desenvolvimento humano e educação: diversidade e inclusão. In: LEPRE, R. M.; MARTINS, M. F. A. Práticas em educaçáo especial e inclusiva na área da deficiência mental. CAPELLINI V. L. M. F. (Org.). - Bauru: MEC/FC/SEE, 12 v, v. 3, 2008.

MARIA, L. P. Posiçáo do professor de sala de aula de integraçáo inversa frente às dificuldades de aprendizagem de pessoas com diagnóstico de deficiência intelectual. 2011. 84 f. Monografia (Especialização em Desenvolvimento Humano, Educação e Inclusão Escolar) — Universidade de Brasília/Universidade Aberta do Brasil, Brasília, 2011.

MANTOAN, M.T.E. Inclusão escolar: O que é? Por quê? Como fazer? São Paulo: Moderna, 2003.

MEZZAROBA, S.; NAGAO, R.M.S. A sala de recurso: uma estratégia diferenciada para complementar o processo de aprendizagem. Revista Eletrônica de Educaçáo, v. 1, n. 2, jan./jul. 2008.

MOREIRA, L.M.A.; CASTRO, J.; SANT’ANA, M. D. M. Diversidade na Escola: aspectos genéticos e consideraçôes psicopedagógicas. 2. ed. Bahia: EDITUS, 2004.

OLIVEIRA, R. P. Da universalizaçáo do ensino fundamental ao desafio da qualidade: uma análise histórica. Revista Educaçáo e Sociedade, Campinas, v. 28, n. 100 - Especial, p. 661-690, out. 2007.

OLIVEIRA, R. M. A aprendizagem matemática no contexto da sala de recursos: interaçóes e adequaçóes curriculares no processo ensino-aprendizagem. 2011. 141 f. Monografia (Especialização em Desenvolvimento Humano, Educação e Inclusão Escolar) — Universidade de Brasília/Universidade Aberta do Brasil, Brasília, 2011.

OPS. Organização Panamericana de Saúde. Educación para la salud: un enfoque integral. Washington: OPS, 1995.

PARANÁ. Instruçáo No 013/08 - Secretaria de Estado da Educação. Superintendência da Educação. SUED/ SEED. Estabelece critérios para o funcionamento da Sala de Recursos para o Ensino Fundamental - séries finais, na área da Deficiência Mental/Intelectual e/ou Transtornos Funcionais Específicos. Curitiba, 2008.

PLETSCH, M. Repensando a inclusáo escolar de pessoas com deficiência mental: diretrizes políticas, currículo e práticas pedagógicas. 2009, 254f. Tese (Doutorado em Educação) - Universidade do Estado do Rio de Janeiro, Rio de Janeiro, 2009.

ROCHA, H. F. O atendimento educacional especializado no processo de inclusáo: relato de uma experiência na sala de recursos. Petrópolis, 2009. 41 p. Monografia (Especialização em Educação Especial) - Centro de Ciências Humanas e Sociais, Escola de Educaçáo, Departamento de Fundamentos em Educaçáo, Curso de Pós-Graduação Lato-Sensu em Educaçáo Especial, da Universidade Federal do Rio de Janeiro/Cead, Petrópolis, 2009.

ROPOLI, E. A. et al . A educaçáo especial na perspectiva da inclusáo escolar: a escola comum inclusiva. Brasília: Ministério da Educação, Secretaria de Educação Especial: Fortaleza, Universidade Federal do Ceará, v. 1, Coleção A educação Especial na Perspectiva da Inclusão Escolar, 2010.

SANT'ANA, I.M. Educação Inclusiva: Concepçōes de Professores e Diretores. Revista Psicologia em estudo, Maringá, v. 10, n. 2, p. 227-234, 2005.

SANTOS, L. H. C.; PIMENTEL, R. F.; ROSA, L. G. D.; REGINA, S.; MUZZOLON, B.; ANTONIUK, S. A.; BRUCK, I. Triagem cognitiva e comportamental de crianças com dificuldades de aprendizagem escolar: um estudo preliminar. Revista Paul Pediatria, v. 30, n. 1, p. 93-9, 2012.

SILVA, F.C.T. Espaços, tempos e professores das salas de recursos e das salas comuns: expressōes de culturaavaliação de habilidades motoras de uma criança com paralisia cerebral incluída em contexto escolar regular escolar. In: 29a Reuniáo Anual da ANPEd, 2006, Caxambú-MG. Educação, Cultura e Conhecimento na Contemporaneidade: desafios e compromissos. Rio de Janeiro: ParkGraf, 2006. p. 1-5.

SILVA, C. L.; LEME, M. I. S. O Papel do Diretor Escolar na Implantaçâo de uma Cultura Educacional Inclusiva. Psicologia Ciência e Profissáo, v.29, n.3, p. 494-511, 2009.

TELES, F. M.; RESEGUE, R.; PUCCINI, R. F. Habilidades funcionais de crianças com deficiências em inclusấo escolar: barreiras para uma inclusão efetiva. Revista Ciência \& Saúde Coletiva, v. 18, n. 10 p. 3023-3031, 2013. 
TESSARO, S. N. Inclusáo Escolar: concepçôes de professores e alunos da educaçấo regular e especial. Associação Brasileira de Psicologia Escolar e Educacional, 2007. Disponível em: <http://www.abrapee.psc.br/artigo20. htm>. Acesso em: 31 mai. 2012.

TEZZARI, M. L.; BAPTISTA, C. R. Construir redes: serviços de apoio em educação especial. Reflexáo e Açáo (UNISC. Impr.), v. 17, p. 1-17, 2009.

UNESCO. Declaraçáo de Salamanca sobre princípios, política e práticas na área das necessidades educativas especiais 1994, Espanha, UNESCO 1998.

\section{Correspondência}

Adriana Zilly - Universidade Estadual do Oeste do Paraná, Campus de Foz do Iguaçu. Avenida Tarquinio Joslim Santos, 1300. Jardim Universitário, CEP: 85870-650 - Foz do Iguacu, Paraná, Brasil.

E-mail: aazilly@hotmail.com - leo_triaca@hotmail.com - jofaller@hotmail.com - reisobrinho@yahoo.com.br - marieta_fs@yahoo.com.br - m_lourdesdealmeida@yahoo.com.br

Recebido em 08 de abril de 2014

Aprovado em 21 de julho de 2014 
